\title{
Cardiovascular diagnostic information about blood pressure, arterial stiffness and atrial fibrillation is contained in oscillometric blood pressure profiles and is extractable by mathematical analysis
}

David Allan Hullender ( $\sim$ hullender@uta.edu )

University of Texas at Arlington https://orcid.org/0000-0003-2142-9167

Olen R. Brown

University of Missouri

\section{Research}

Keywords: arterial fibrillation, arterial stiffness, blood pressure measurement, oscillometric device, waveform analysis.

Posted Date: December 27th, 2019

DOI: https://doi.org/10.21203/rs.2.19293/v2

License: (9) This work is licensed under a Creative Commons Attribution 4.0 International License.

Read Full License 
The authors have withdrawn this preprint from Research Square 